\title{
Connectable Internet Address Object Point using the Active Accessibility
}

\section{Mohammed Zaki Hasan \\ mzhasan@uomosul.edu.iq \\ College of Computer sciences and Mathematics \\ University of Mosul, Iraq}

Manar Y. Ahmed

Received on: 02/02/2006

\section{ABSTARCT}

Accepted on: 16/11/2006

This paper focuses on how building application components using Visual Basics that are accessible to people or computer users from client with disabilities. The main purpose of it is to perform a job by the server that can't be used by some with a disability essentially denies that otherwise qualified person job. An application was designed through connection point by the COM+ programming. The application performs a security for both the client and server computers and have the ability of disable option to prevent the user from making trouble in the computer.

Keywords: Application Component, Internet protocol, Object, Client, server, Connection Point,

$$
\begin{aligned}
& \text { نقطة تواصل عنوان كائن الإتترنت القابلة للانصال باستخدام إمكانية الوصول النشطة } \\
& \text { منار يونس كثموية } \\
& \text { كلية علوم الحاسوب و الرياضيات، جامعة الموصل فئل } \\
& \text { تاريخ قبول البحث: 2006/11/16 }
\end{aligned}
$$

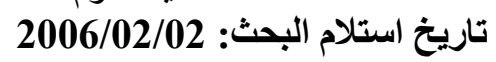

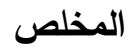

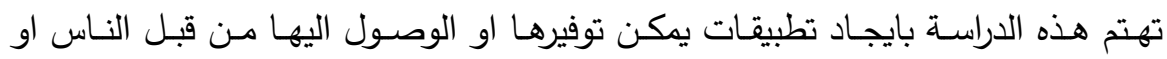

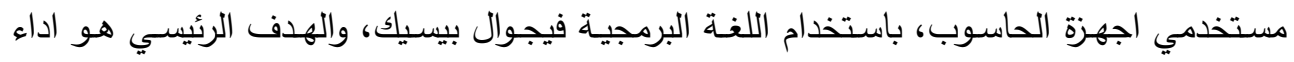

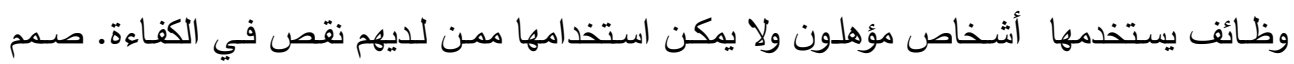

$$
\begin{aligned}
& \text { التطبيق من خلال الانترنت بوساطة برمجة +COM. هذا التطبيق يؤدي وظيفة معينة لكل من }
\end{aligned}
$$

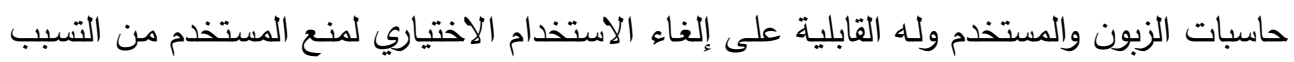

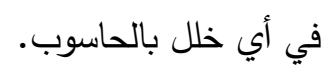

$$
\begin{aligned}
& \text { الكلمات المفتاحية: تطبيق، بروتوكول الإنترنت، الكائن، العميل، الخادم، نقطة الاتصال. }
\end{aligned}
$$

\section{Introduction: -}

A disability is simply a physical or mental limitation that makes performing a given task difficult. Any application developed with Visual 
Basic should have certain features that makes accessible. These features include the most important considerations in the design of application such as user data input from the keyboard, mouse, light pen, and others.

In this paper, an application was designed through creating connection points by the $\mathrm{COM}+$ programming for all components in development application. This is done by identifying the Internet Address (IP) for one computer (server) as an object where it is disability for end user, and other computer (client computer) can access the server through the accessible connection.

\section{Creating the Internet Protocol (IP) as a connectable object:-}

a. The definition of the structure: -

The more common the interfaces to the client and the object, the more intertwined their relationship is. But regardless of the number of interfaces the object supports, the basic model remains the same: the client calls the methods implemented by the object (server), the object performs the desired service, and then the object returns the results to the client. This type of relationship is rather one -sided- the client always makes request of the object [1].

Through this relationship, it can create additional relationship between the client and the server; by creating the Internet Protocol (IP) as an object to make connection between both (client and server).

$\mathrm{COM}+$ supports connection points, a technology that enables an object to "talk back" to its client. Objects that support connection points are often called connectable objects [1].

$\mathrm{COM}+$ was used to program the client as "accessible" to the object and "disability" for the end user.

Figure 1-A shows the layout of the connectable object using a source interface to "talk back"

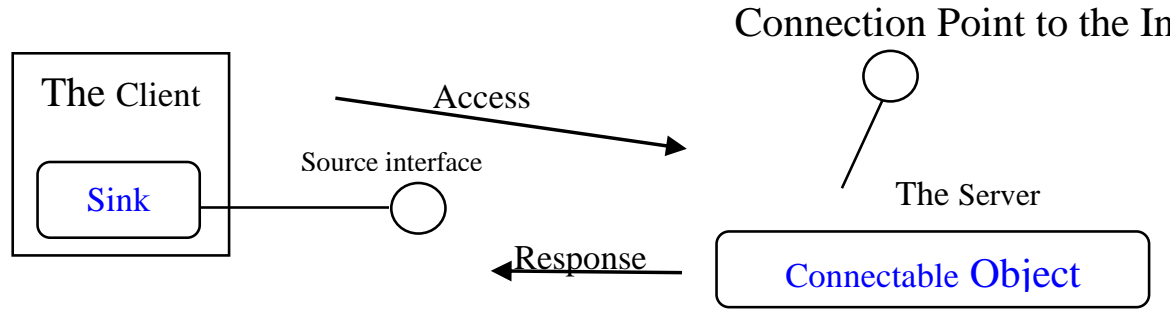

Figure 1-A: layout of the connectable object using a source interface to "talk back" 
Figure 1-B shows the layout of the connectable object using a source interface to "Accessibility of the Internet Protocol (IP)"

Connection Point to the Internet

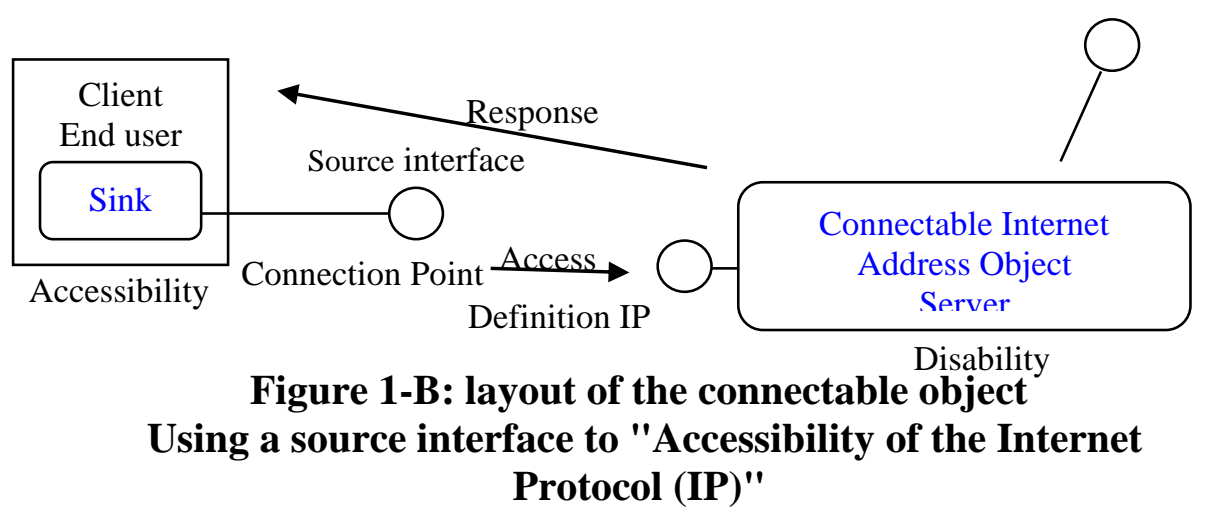

Connection points that are described in the above figures define a source interface as outgoing interface, which is an interface defined in the object but implements by the client. A sink object, which resides within the client, is the object that implements the object's source interface, while the connection point at the server defines the Internet Protocol (IP) as an object, and gives the accessibility property to the end user, and the disability for the addressing.

\section{b. Using Active Accessibility: -}

Active $\mathrm{X}$ controls are the best known type of the object that uses the technology "talk back". Sometimes objects use connection point to get further information from the client about the service it has requested [2].

The active accessibility uses component object model technology to expose interfaces that provide a common means of communication among applications. Without active accessibility, establishing these communications can be difficult.

In order accessibility aid software written in visual basic to communicate with system software or the details of system software such as the configuration of the network places, and the installing of the Internet Protocol (IP) for the host computer, it's required to know or discover a lot of details about the specific types of software. 
So when any software created by active accessibility, the accessibility at the end user doesn't need to know any application-specific details. They can find out what is on the screen as entering the information, and how to use it from the common interfaces exposed by active accessibility. The accessibility for the client aids the end user to access the host through entering the Internet Protocol (IP) for host computer. The server is the software application that is exposing accessible interfaces so that the client can easily enter and retrieving information.

Finally, the question is how to make the visual basic application available as both server and client.

The answer is that active accessibility is still very new, and before starting building the VB project, it is necessary to load the Microsoft Active Accessibility (SDK) [3].

\section{c. Obtaining an Internet Protocol Address}

Most Internet protocol (IP) represents a single host on the internet. To make sure that each host receives a unique Internet protocol (IP) Address, the process of obtaining address most carefully managed.

To obtain an Internet protocol (IP) Address, for our desktop machine, or laptop, we must run windows and open up a command prompt, as shown in figures below.

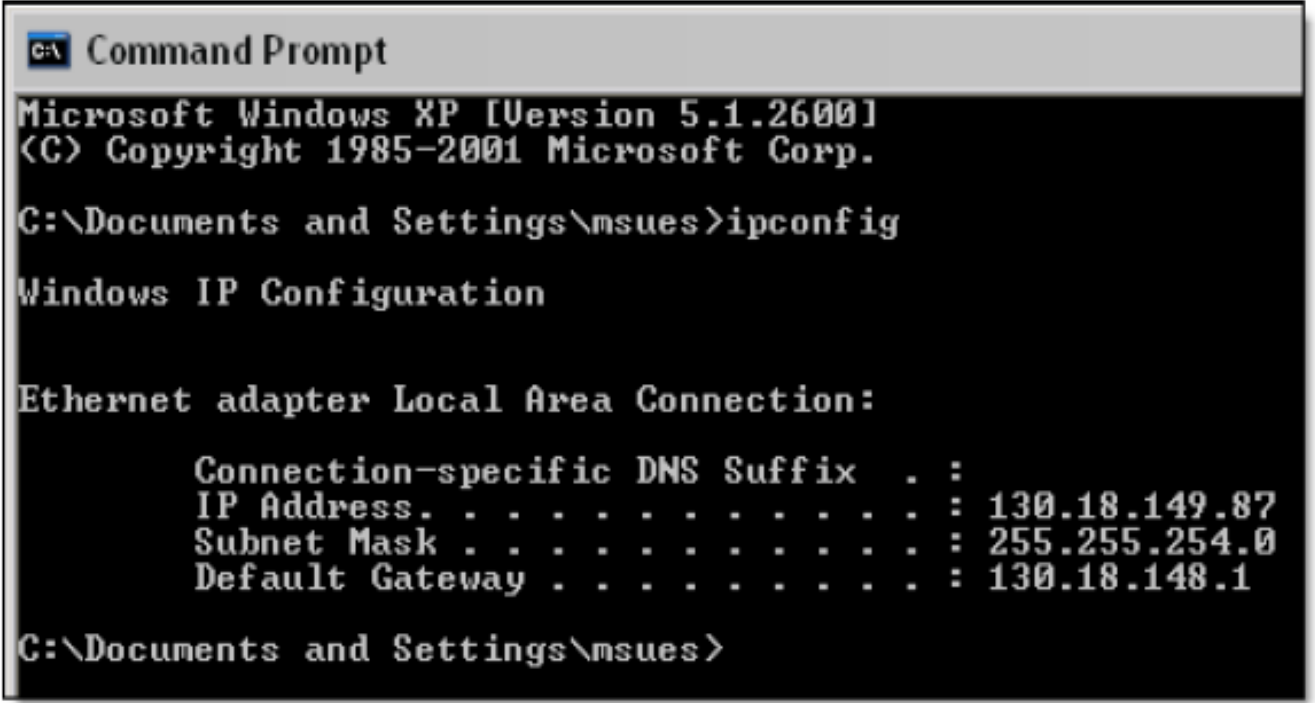

Figure 2: Windows command prompt 
The command IPconfig is used to display information of Internet protocol (IP) Address and change the configuration of Internet protocol (IP) Address. Finally, we must save the results of these (renew, release) to file with CAP extension. It may be difficult to user, so this system is programmed to fair and efficient manager the Internet protocol (IP) Address, and prevent user from goes to use the command prompt form using the term of active accessibility with little or no complexity.

\section{d. Create Connectable Internet Protocol (IP) Object : -}

$\mathrm{COM}+$ enables to write reusable software that allows clients and objects to communicate across process and the host computer boundaries. $\mathrm{COM}+$ is based on client, classes and objects. Classes are defined in binary files called server. These servers make it possible for client to create and connect to objects whose code lives in separate binary file.

Out-of-process communication would require using some interprocess communications mechanism such as Dynamic Data Exchange (DDE). $\mathrm{COM}+$ supports remote method calls across process boundaries as shown in figure2 [4].

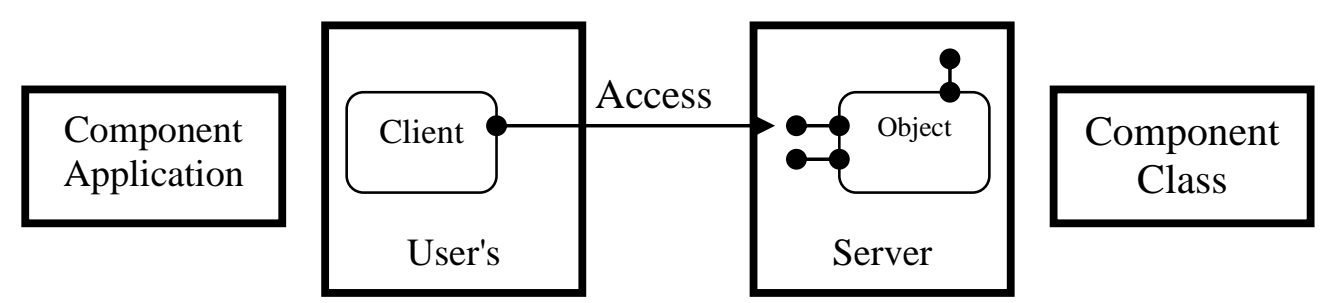

Figure2: The Relationship between a client and out-of-process server.

The communication between the client and the object takes place through a set of publicly accessible properties and methods that are known as an object's public interface. The class author must use the public interface to expose the object's functionality to the client. As shown in the below sources code that uses a variable based on a class type to access an object's public

Dim AccessIP as IP Addressing

Set Access IP = new IPAddressing ' access property. 
At the beginning, the interface of application was defined and designed, which is considered as the major goal of COM+. In order to allow methods to be invoked on component objects as efficiently as possible, Win32 API should be used where they are available to all applications through series of operating system DLLs, because the COM+ library is a set of DLLs and EXEs installed on any COM-enable computer. A client can link to a DLL at run time and call exported functions. Then client application must call upon the services provided by the COM library to create and connect object. [5]

After the reference in the visual basic interface programming, it can create objects from classes in the component and then write the source code as shown in above paragraph using the object's properties, methods, and events.

\section{The Internet Protocol (IP) Programming: -}

In the classic client-server model, the client sends out request to the server, and the server does some processing with the requests received, and returns a reply to the client. An example of simple client-server component application would be that of Web-server. A client (Internet Explorer or Netscape) sends out a request for a particular web page, and the web-server receives and processes this request, and sends out a reply, which in this case, is the web page that was requested. The web page is then displayed on the browser (client).

In this implementation of the client/server, onloading database processing to the server, the database server must accept any SQL (Structure Query Language) from the client computer, execute the query and then return the answer to the client computer [6].

In order to provide access to the TCP network services, the application allows the client computer to access the server. This is done by entering the right name of the server or the Internet Protocol (IP) address, it is (computer1) or (192.20.0.10), and then click the connected command bottom, and wait for minutes to establish the connection between the client and server computers.

Each TCP/IP host is identified by a logical Internet Protocol (IP) address. A unique Internet Protocol (IP) address is required for each host and network component that communicates using TCP/IP [7].

The internet community originally defined five address classes to accommodate networks of varying so in this paper, we have built a sample 
network between two computers, one of them is a host and the second is a client. Thus we used class $\mathrm{C}$ which is a three high-order are bits always set to binary ( $\left.\begin{array}{lll}1 & 1 & 0\end{array}\right)$. The next 21-bits complete the network ID. The remaining 8 -bits represent the host computer.

The TCP is used to create and maintain to a computer. The computers are able to share information through the connection. The client must know the server's name or the Internet Protocol (IP) address, this is done by creating two forms with two Winsock controls which enable to connect to a remote computer and exchange data between both client and server computers. Then setting in the RemoteHost Property of the Winsock control [8].

The client must also know the port number on which the server will be listed on, set in the RemoteHost Property of the Winsock control, as shown in the following source code.

Private Sub cmdConnect_Click()

Winsock1.RemoteHost $=$ "11.0.0.1" 'Change this to your host ip

Winsock1.RemotePort $=1088$

Winsock1.Connect

shpGo.Visible $=$ True

End Sub

txtItem.SetFocus

When the client requests a connectionRequest Event occurs, and accepts method used within the Connection Request event to complete the connection, as shown in the following figure of client-form.

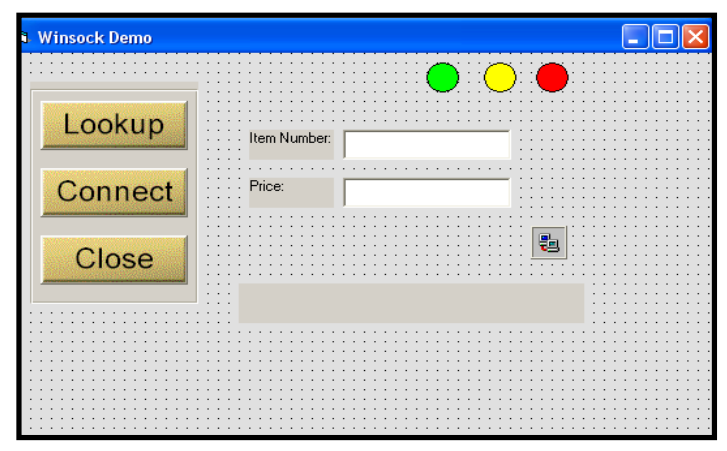

Figure3: The Client form 


\section{e. The Description of the Application:}

The Internet protocol (IP) based networks use Internet protocol IP addresses to establish sessions. In order to communicate over the Internet, a system must have an IP address [9].

This application is a real world example, where the clients request some information from the server and the server retrieves some specific information from the database and sends the retrieved information back to the client. The server form is designed to accept the item number, or information sent from the client, which the customer wants to buy something, by credited card, visa, or others, and look up the associated price in a database. The server then sends the information back to the client. The connection to the database on the internet is made in the Data Arrival event of the Winsock control. If the connection to internet failed, or the low connectivity occurs, then the user uses the IPconfig commands such as (releases, renew) to establish the connection again which shown in figure3 above. The server form which is shown in figure4 below describes the user, the details information about the Internet Address (IP), status connection and other information's, these information can be used by the server to recognize a known client [9]. The server can use this information to implement a variety of policies such as handing out the Internet Protocol (IP) and others. In the server discovery message, the client also specifies the right connection though the parameter access objects to join to the internet.

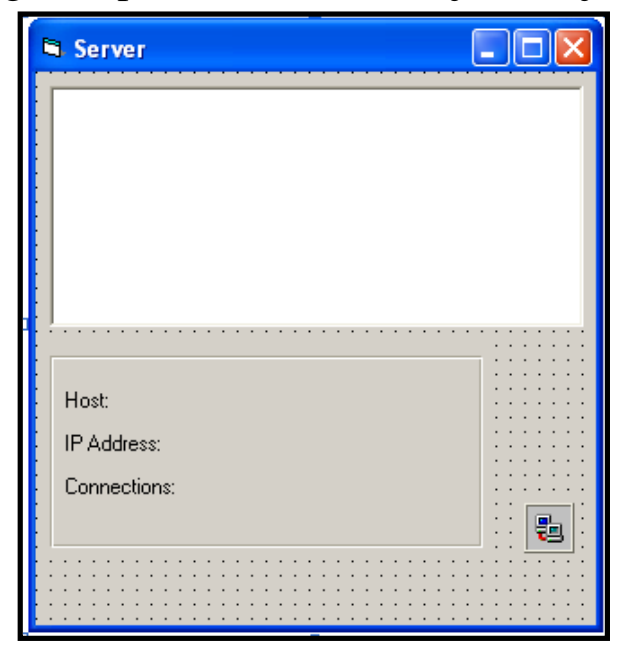

Figure4: The Server Form 


\section{Conclusions: -}

In this paper, an application was designed through connection points by the $\mathrm{COM}+$ programming for all components in development application. The COM software was built using Visual Studio. More flexibility was added for the user of computer either in the server, or on the client to enter the IP addressing and performing connection to the network. Beside that the security of both client computer and the server was implemented through the idea of COM proxy. Finally the application has the ability of disable options for the user to prevent him/her from making trouble in the computer, and able others options for access the network. 


\section{REFERENCES}

[1] Library of Congress Cataloging-in-Publication Data (1998) Programming Distributed Applications with COM and Microsoft Visual Basic 6.0 / Ted Pattison , United States of America, Microsoft Corporation.

[2] Library of Congress Cataloging-in-Publication Data (1999) Desktop Applications with Microsoft Visual Basic 6.0 MCSD Training Kit, United States of America, Microsoft Corporation.

[3] Library of Congress Cataloging-in-Publication Data (1999) Desktop Applications with Microsoft Office Resource Kit, United States of America, Microsoft Corporation.

[4] Library of Congress Cataloging-in-Publication Data (1999) Inside Microsoft COM+ Base Services, United States of America, Microsoft Corporation.

[5] Library of Congress Cataloging-in-Publication Data (1999) Distributed Applications with Microsoft Visual Basic 6.0 MCSD Training Kit, United States of America, Microsoft Corporation.

[6] AL_layla, M. Zaki (2003) "protection Data-in-motion Stored in Database System", Ms.c. Thesis, Iraq, University of Mosul.

[7] Duncan Anderson (2001/2000) IP Addressing and Subnetting including IP v 6.0, Osborne/McGraw-Hill.

[8] Joe Hummel (2004) Building Applications and Components with Visual Basic.Net, USA, by Person Education, Inc.

[9] Jeanna Matthews (2005)Computer Networking Internet Protocols In Actions, USA, by John Wiley \& Sons, Inc. 